\title{
How Factorial Survey Analysis Improves Our Understanding of Employer Preferences
}

\author{
Patrick McDonald*
}

\begin{abstract}
Factorial Survey Analysis (FSA) is an analytical tool that presents respondents with fictional situations ("vignettes") to be rated or judged. In this paper we study the use of FSA in labour market sociology, with a particular focus on employer-based surveys, and what they can teach us about hiring preferences. FSA is useful in this context as it targets employers directly and comes close to a causal design. This review article seeks to pinpoint the contributions FSA has made to the field, identify its limits and propose topics in which it may be useful. Keywords: employer preferences, employer surveys, recruitment
\end{abstract}

\section{Wie Factorial Survey Analysis unser Verständnis von Anstellungspräferenzen von Arbeitgebern verbessert}

Zusammenfassung: Die Methode der Factorial survey analysis (FSA) präsentiert UmfrageteilnehmerInnen fiktive Situationen (vignettes) und bittet sie, diese zu bewerten. Dieser Artikel untersucht die Verwendungszwecke der FSA im Bereich der Arbeitsmarktsoziologie. Die FSA erweist sich als eine nützliche Methode, da sie Arbeitgeber direkt befragt. Dadurch ermöglicht sie eine bessere Identifikation der kausalen Zusammenhänge. Diese Literaturübersicht zeigt den wichtigen Beitrag, den die FSA in dieser Fachrichtung geleistet hat, und weist auf weitere Anwendungsmöglichkeiten für die FSA hin.

Schlïsselwörter: Arbeitgeberpräferenzen, Arbeitgeberumfragen, Personalbeschaffung

\section{Comment la factorial survey analysis améliore notre compréhension des préférences des employeurs}

Résumé: La Factorial survey analysis (FSA) est un outil analytique permettant le jugement de situations fictives ("vignettes») dans une enquête. Nous étudions ici comment la FSA a été utilisée en sociologie du marché du travail en nous focalisant sur des enquêtes d'employeurs et les préférences de recrutement. Dans ce cadre, la FSA permet de cibler les employeurs et d'identifier des liens s'approchant de la causalité. Cet article de synthèse vise à identifier les contributions et limites de la FSA, et propose de nouveaux sujets pour lesquels cette méthode peut être utile.

Mots-clés: préférences des employeurs, enquêtes des employeurs, recrutement

University of Lausanne, Life Course and Inequality Research Centre (LINES), CH-1015 Lausanne, patrick.mcdonald@unil.ch. 
The tools and strategies employers use in their decision-making are of prime interest for labour market sociology. However, the bulk of research is on the supply, or employee, side of the labour market. ${ }^{1}$ This is partly due to convenience - labour force surveys in particular are widespread and provide easy data access to researchers. Yet while this may provide some insight into the forces at work in the labour market, it is an incomplete picture. Labour force surveys rely on the answers and perceptions of employees and the unemployed, and require inferences and assumptions on the part of the researcher to discern the employer's behaviour. This asymmetry is all the more problematic since in the employer-employee relationship, it is the employer who wields most of the decisional power, the ability to "hire and fire" being of utmost importance in any consideration of labour market behaviours (Behrenz 2001).

The informational asymmetry has begun to be corrected in recent years, with a stronger focus on employers in the analysis of labour-market dynamics. Employer surveys take various forms - from traditional surveys (e. g. Taylor and Walker 1994; Breen et al. 1995), to correspondence audit studies where fictitious applications are sent for jobs (e. g. Pager et al. 2009; Protsch and Solga 2015), content analysis of job advertisements (e. g. Bennett 2002; Sacchi et al. 2016), and to qualitative interviews (e. g. Larsen and Vesan 2011; Bonoli and Hinrichs 2012). Additionally, a strand of single-firm studies has developed in the past 20-30 years, whereby researchers are granted extensive access to a company's internal data and archives (e. g. Fernandez and Weinberg 1997; Petersen et al. 2000).

While these techniques succeed in addressing the lack of employer study in labour market questions, they each have their drawbacks. Surveys and interviews are subject to social desirability bias (Pager and Quillian 2005), audit studies, especially in-person audits, require significant time and resources which increase considerably with the depth of analysis sought (Pager et al. 2009; Protsch and Solga 2015), content analyses can only analyse information an employer chooses to make public, while firm-based studies rely on the goodwill of companies and provide information limited to a single (and possibly not very representative) firm (Fernandez and Weinberg 1997). These drawbacks mean that research on employers continues to be far less common than on employees.

This paper focuses on a different technique used to study employers' preferences and choices: Factorial Survey Analysis (FSA). This type of analysis uses tailor-made vignettes, presented to targeted respondents, to create data for analysis. FSA is not new - the idea has its origins in Peter Rossi's 1951 dissertation, and was codified in

1 There are notable exceptions to this, particularly in the fields of organisational sociology, management studies, and behavioural economics (see for example Taylor and Walker 1994; Holzer et al. 2006; Taylor 2005). 
Rossi and Nock (1982), who propose a survey technique that presents respondents fictional circumstances to rate. Since the 1980s it has slowly been taken up by social scientists, though largely in the fields of crime and deviance (Wallander 2009) as well as marketing (Green and Srinivasan 1990). Since the early 2000s, however, labour market research has used FSA with increasing frequency. FSA requires respondents to make judgements based on fictional situations presented to them. This means employers can be asked about their decision-making processes without relying on memory recall, or running the risk of divulging confidential information. Researchers are able to focus on specific factors and to manipulate different factors they wish to test, all the while controlling for other confounding influences. If well designed, they can diminish the probability of social desirability bias. As an experimental technique, it has the benefit of making causal inference more accessible, because it avoids unobserved heterogeneity between individuals and allows the researcher to have complete control over, and knowledge of, variables and stimuli. Nevertheless, it measures stated intentions rather than actual behaviour, and often only small sample sizes. Moreover, while results are highly internally valid, questions remain about external validity.

This review article will show what we have learned through FSA-based employer surveys and, in light of its strengths and weaknesses, propose areas for its future use. FSA is especially well suited to the analysis of signals because different signals and indices, such as education, race and nationality, gender and age profiles, can be varied and randomised. FSA has also been used to study queuing theory, whereby applicants are placed in a virtual queue based on their characteristics, as well as how employers may substitute one quality for another or engage in trade-offs in hiring decisions, and the preferences of employers for certain profiles over others. Drawing on the existing literature, we will argue that its application in labour market sociology allows us to glean new information about recruitment practices and employer decision-making, thus going some way towards correcting the lack of information from the employer side of the labour market equation. FSA can be combined with other analytical techniques to form a multi-dimensional picture of employer-employee dynamics more broadly, and employers' recruitment behavioural intentions more specifically, as well as lending external validity to the results, an area where FSA, whose results are not likely to be generalisable or representative, has some weakness.

This article is structured as follows. First, we briefly outline the technical and theoretical background of FSA, the advantages to its use and present some criticisms. We then review the use of FSA to survey employers in the main areas of its uptake: older workers, ethnic/national discrimination, as well as education, before moving to more recent uses of FSA and suggesting some future directions. A conclusion summarises the review. 


\section{Factorial Survey Analysis - Background and Advantages}

Aside from Rossi's (1951) and Rossi and Nock's (1982) foundational work on factorial survey analysis, the theory and methodology behind FSA is described in detail by Jasso (2006), Wallander (2009) and Auspurg and Hinz (2015). A summary of important background information follows here. FSA examines the basis and influences of social judgements by posing a series of fictional vignettes to respondents, and asking them to make a judgement based on the information provided. Vignettes are made up of dimensions (variables), the characteristics of the vignette that vary in their levels (values) (Wallander 2009). Examples include vignettes based on the housing market, where the neighbourhood, price, and age of the house are the varying dimensions, or on punishment for criminals, where the crime, circumstances, and mental state of the criminal may be the varying dimensions (Auspurg and Hinz 2015). Such surveys are used either to elicit a normative judgement - where a respondent is asked to judge how they think something should be (choosing a punishment, rating the fairness of a situation) - or a positive belief - how they think something is (reflect on how they would behave in a given situation, estimate an outcome) (Jasso 2006, 335-336; Wallander 2009, 509).

Similar techniques are popular across a broad range of social, economic, and commercial research. FSA is closely related to conjoint analysis, or discrete choice experiments, a technique frequently used in marketing and recently picked up by political scientists, where consumers (or voters) are shown different products with similar features and asked to choose between them (Green et al. 2001; Ryan et al. 2001). Despite their different names and theoretical backgrounds, these techniques are practically the same (Hainmueller et al. 2014). Together with other lesser-used methods such as Paper People Studies and Policy Capturing Studies, they form what is termed "Experimental Vignette Methodology" (EVM) (Aguinis and Bradley 2014).

One pitfall of statistical analysis of survey data is the difficulty of disentangling causal relationships. While observational data can detect correlation, it is difficult to pinpoint causality without using sophisticated statistical designs (Winship and Morgan 1999). As an alternative, Winship and Morgan suggest a return to "experimental thinking." FSA fits this call by embedding an experiment within a survey. By having complete control over and fully randomising all the inputs (in this case, the vignette dimensions), causal relationships can be identified. The survey designer is aware of all the information contained in the survey, all of which is uncorrelated, meaning that the influence of unobserved heterogeneity and collinearity can be discounted. This experimental design is key to FSA's attractiveness as a tool for studying labour market issues.

FSA's format has a number of further advantages for labour market sociology in comparison to other analysis techniques such as surveys and administrative data. First, it plugs an important knowledge gap by analysing stated intentions directly, 
rather than parsing information about employers' decision-making second-hand. FSA questions employers in a way that more closely emulates their real-life decisionmaking, and is less easily manipulated by its respondents than survey analysis - the go-to for most research in the social sciences. Additionally, decision-making is a multidimensional process, where many different factors come into play simultaneously. It is therefore useful to present them all at once, in a manner that makes sense to respondents, to ascertain the importance of certain vignettes rather than rely on self-assessment.

We are interested specifically in the benefits of using FSA in labour market sociology, and especially as a way of measuring employer decision-making in recruitment processes. Here, it has a number of advantages: It provides a good simulation of the hiring process and reflects the multidimensional nature of recruitment decisions. Furthermore, it is advantageous for studying employer's decision-making processes, albeit hypothetically, over other analytical strategies. For example, audit studies $^{2}$ have the advantage of analysing real hiring processes, but they either give up detail to gain this realism - the most that can be hoped from a correspondence audit study is to know if certain profiles would be invited to interview - or, in the case of in-person audits, require large investments and the resolution of ethics questions before being implemented. FSA, on the other hand, can ask employers questions about salary, company fit, suitability for training, amongst others. Such questions add necessary depth to our knowledge of employers' practices and reinforce the utility of FSA as an analytical tool for decision-making processes, though as we lay out in the next section, it is not without its drawbacks.

\section{Factorial Survey Analysis - Criticism}

FSA can be criticised in a number of ways. Commonly, vignette studies are dismissed as not reflecting real life, in terms of the urgency of decision-making, the make-up of the sample, or the design of the vignettes. Responding to a series of vignettes may also lead to fatigue and thus respondent-induced error. A number of significant concerns regarding vignettes' real-life relevance come out of the work of Pager and Quillian (2005), who use a follow-up telephone interview to a correspondence audit study to show that employers' responses in surveys do not always reflect their

$2 \quad$ Audit studies are a subset of field experiments carried out by sending fictional applications for real jobs - either "in-person audits" where a written application is followed up with a person sent for an interview, or "correspondence audits," which rely only on a written application (Gaddis 2018). They vary 1-2 dimensions, typically race or gender, and analyse whether this artificial variation leads to lower or higher overall recall to interviews or offers of employment. This is often supplanted with qualitative data on a selection of the firms and organisations targeted (see Pager et al. 2009; Protsch and Solga 2015). 
real-life behaviour. ${ }^{3}$ They pinpoint three key weak points of survey-based research, in which FSA can be included and which form a useful basis for the discussion of its weaknesses: (i.) social desirability bias, (ii.) abstract situations and external validity, and (iii.) priming intensity.

First, social desirability bias can be a crippling challenge for any survey-based research project where subjects are at least partially aware of their participation. Respondents are likely to downplay any bias against women, minorities, and/or people with a criminal record when answering a vignette survey as opposed to an actual recruitment process (Pager and Quillian 2005, 364-365). Vignettes could thus underestimate the actual effects of discrimination in reality, especially if respondents are able to guess at the purpose of the survey. There are methods, however, that can be used to mitigate social desirability bias in FSA. Auspurg and Hinz (2015) outline two key ways by which this can be achieved. First, by the subtlety of questioning that FSA can facilitate: rather than asking questions on contentious issues outright, a well-designed factorial survey will embed them in a set of constantly-changing dimensions, making the dimension in question difficult to discern and therefore minimising the risk of a respondent giving a response motivated by social desirability. This is linked to the second advantage of FSA in minimising social desirability bias: the need to use trade-offs when judging vignettes. With several dimensions changing in each vignette, a respondent often must make a decision about which perceived negative characteristic is more or less important, making it difficult to give socially desirable answers across the board. It is clearly not possible to avoid socially desirable answers altogether. A well-designed factorial survey, however, should be able to mitigate social desirability to some extent.

Second, a critical issue that arises with data from any simulated rather than real situation is the external validity of the results. ${ }^{4}$ FSA is an exercise in ascertaining behavioural intentions, and does not measure actual behaviour or decisions. Though vignettes are designed to closely resemble realistic scenarios, they cannot do so perfectly and risk being useless without thoughtful interpretation. A profile accepted in a vignette survey may be rejected in real life. This may be partly because of differing circumstances in a specific hiring situation and the availability of more detailed information in reality, but it may also be due to the fact that in an FSA, there is no pressure or urgency to hire, and therefore respondents can accept profiles more easily knowing there will be no consequences. FSA in the employer survey context should therefore be considered hypothetical baseline intentions which may vary from actual behaviour depending on actual circumstances. Moreover, FSA-

3 Hainmueller et al. (2015), in contrast, find that behaviour in experimental settings closely mirrors that displayed in real life.

4 McDermott defines internal validity as "the extent to which an experimenter can be confident that his or her findings result from experimental manipulation" $(2011,28)$, and external validity as "the generalizability of findings from a study, or the extent to which conclusions can be applied across different populations or situations" $(2011,34)$. 
based research is not readily generalisable. By design, it chooses a small selection of profiles that may not reflect the reality of a wider context. In recruitment terms, it is likely to focus on a handful of specific jobs, and drawing conclusions for the labour force in the aggregate would therefore be unwise. One way of addressing this weakness is to combine a factorial analysis with other data sources - labour force surveys or audit studies, for example - and compare the results.

Third, priming intensity refers to the detail of description of the subject or situation in question. Just as meeting someone in real life and reading their description on paper are two different things, so can the type of description vary significantly. A vague CV leaving a respondent to "fill in the gaps" may lead to an entirely different result than a long and detailed résumé complete with photo. Priming may also refer to the realism of the stimuli presented. This is a challenge for FSA in recruitment studies in particular, when the vignettes are often designed to simulate actual CVs. Researchers must balance the informational needs of the survey with the necessity of presenting realistic CVs, which (depending on the labour market context) are unlikely to contain some of the information of interest to researchers, particularly if this includes personal and family-related information. A series of $\mathrm{CVs}$ that do not conform to accepted norms may prime respondents less well than a series resembling actual CVs, which may in turn contain less information and therefore be less useful in analytical terms.

Various other design problems may beset factorial surveys. Poor design may lead to the presentation of illogical situations. Given that a vignette combines several different dimensions, it is possible that without proper caution, illogical profiles may appear in a survey - for example, a doctor earning only $\$ 300$ per month, or a 20-year old who has been unemployed for the last five years looking to enter the labour market. Such illogical cases may lead to respondent disengagement, which in turn can result in unreliable data. Avoiding such issues requires extra reflection on the part of the research designer to create a vignette universe that is realistic and captures all necessary information. ${ }^{5}$

Similarly, respondent fatigue due to survey length and complexity of the survey may cause problems if not properly addressed. Having too many vignettes to analyse and/or too many dimensions per vignette can result in cognitive overload, and therefore inconsistent evaluations. Sauer et al. $(2011,98)$ estimate the limit for general population surveys to be at a maximum of around 20 vignettes per respondent, each with at most 12 dimensions, though this may be increased for studies of professionals.

5 The methodological literature suggests that these implausible or illogical vignettes be dealt with in two steps: First, by avoiding them in the initial choice of dimensions and levels as best as possible, while maintaining a reasonable breadth of dimensions and levels; second, by dropping illogical vignettes when selecting the subset of the vignette universe to be used in the survey, while ensuring that the dimensions within the selection remain orthogonal in order to preserve the ability to ascertain causal relationships (Auspurg and Hinz 2015, 21-22). 
The weaknesses of FSA can be summarised, then, as lacking external validity, its hypothetical nature - which may be exacerbated by poor design or non-realistic stimuli - and as lingering concerns that it does not fully address social desirability problems. While these concerns do not discredit its use altogether (Pager and Quillian 2005, 372) they request for prudent and conservative interpretation of results obtained from FSA. In the employer-side context, this means considering results as minimum baselines, or preferences, expressed in a hypothetical context, not as exhaustive or predictive, nor as a concrete measure of actual behaviour.

\section{$4 \quad$ Applications in Labour Market Sociology}

\subsection{General Overview}

As FSA has gained a foothold in labour market sociology, its use in analysing different topics has expanded significantly. Here, we give a general overview before moving to the specific case of FSA targeted directly at employers. FSA is particularly useful in analysing the effect of signals on employers. Signalling theory has its basis in the work of Spence (1973), who argues that due to informational asymmetry, important characteristics of a job applicant - such as their productivity - cannot be observed directly. Recruiters must instead infer these characteristics from what they can observe. Spence divides these observable characteristics into signals, or characteristics that can be changed, and indices, or those that cannot (Spence 1973, 357). Signalling theory has since become one of the linchpins of studying recruitment. Education, in particular, is widely accepted to signal quality in a candidate (Connelly et al. 2011), but empirical evidence has suggested that other characteristics are often used as signals by employers - names can signal ethnicity, participating in sporting activities can signal fitness and be positive for jobs requiring manual labour, and participation in active labour market programmes can either signal diligence and willingness to learn, or discrepancies in necessary knowledge (Liechti et al. 2017). How employers react to these signals and indices in either a CV or a job interview is an essential knowledge in the recruitment process.

Beyond signalling, FSA has also shown its use in queuing theory (Di Stasio 2014, Thurow 1975) - whereby employers will place applicants in a virtual queue based on their qualities, attributes, and indeed the signals present in their CVs or interviews. Including questions on likelihood to hire, or invite to an interview, in FSA can be used to provide information on what characteristics affect the place of an applicant in the job queue, and how this may vary for different jobs.

FSA also provides a useful way of measuring discrimination in hiring and wages. Using traditional survey data, discrimination is difficult to measure, as it is likely to be confounded or correlated with other variables, and untangling the different effects is far from easy. FSA proposes a solution by providing data where variables 
are uncorrelated, meaning that discrimination, or lack thereof, can be identified. Moreover, rather than relying on reported wages and employment statistics to infer possibilities of discrimination, FSA allows direct measurement of stated intentions for various profiles containing different characteristics that may be discriminated against, such as age, sex and ethnicity, as well as the interaction between such variables. Finally, FSA may be able to reduce social desirability problems faced by measuring discrimination through direct questioning, meaning its responses can get closer to reflecting true discrimination. While the mechanics of the hiring process are almost exclusively the domain of employer-based studies, FSA has been used in general population samples to study examples of discrimination, particularly concerning gender. Jasso and Webster (1997) study what people in the US perceive as "just earnings" for men and women. Using a general population sample living in Baltimore in 1974, they find that while both men and women assign higher wages to men the difference is higher amongst male respondents (Jasso and Webster 1997, 76). The analysis is replicated in a companion paper, this time targeted at students in a US university in 1994, which finds that while the gender gap had closed in the eyes of both men and women, female respondents gave more weight to education in wage decisions, to both male and female profiles, than male respondents. Both sexes felt that experience (measured by age) was more important for male candidates than female, but the difference was more pronounced amongst female respondents (Jasso and Webster 1999, 376-378). Ethnic discrimination has also been the subject of FSA, though to a lesser degree than that of sex discrimination. Baert and De Pauw (2014), with a sample of 268 economics undergraduates at Ghent University in Belgium, find that their respondents prefer natives to non-natives, as potential employers, co-workers, and customers.

On the supply, or jobseeker, side of the labour market, FSA has been used to analyse the conditions under which jobseekers will accept a new position, particularly when unemployed or when a partner's career needs to be taken into account. Abraham et al. (2010) use a factorial survey amongst 280 European couples to show that the decision to relocate for work can lead to inter-couple conflict, especially when a member of the couple perceives a reduction in their relative bargaining power, highlighting "the relevance of a couple- or household-oriented approach when labour market processes are studied" (Abraham et al. 2010, 889). Mobility is also partly the subject of a study by Abraham et al. (2013), who use a factorial survey amongst 4000 respondents of the 2011 German PASS survey - almost 2000 of whom were either unemployed or in precarious employment - which seeks to analyse under what circumstances a jobseeker is willing to accept a job offer. They find that while the unemployed are in general more willing to accept a job offer than the employed, and more likely to accept a short-term contract, factors such as needing to relocate were not seen differently. Short-term unemployed were also more likely to accept jobs with "unfavourable" characteristics than long-term unemployed, 
though long-term unemployed showed more willingness to move - partly because of a legal obligation in Germany to do so (Abraham et al. 2013, 299). More recent examples of FSA being used in this context include Auspurg and Gundert (2015), on bargaining power of jobseekers and their willingness to accept short-term contracts, and Bähr and Abraham (2016), on unemployment and willingness to locate, taking into account social capital of unemployed jobseekers.

\subsection{Employer-Based studies}

We undertook an extensive database research to find a representative cross-section of papers that use factorial surveys among samples of employers. We took a twofold approach: first, we searched academic databases (notably Google Scholar and JSTOR) using the keywords "factorial survey," "employers," "labour market," and "sociology." Second, we searched lists of works citing the key methodological contributions: Rossi and Nock (1982), Jasso (2006), and Auspurg and Hinz (2015). From these two sources we compiled a complete list of studies that use FSA directly targeting employers for analysis, which is detailed below. FSA has been used across a number of issues relating to the labour market; several key areas stand out: older workers, discrimination based on nationality, and education, with a move into further subjects in recent times. These three topics plus a review of recent FSA applications in employer-based studies form the basis of our literature review. FSA's use has accelerated in the last few years. Prior to 2010, 12 papers using FSA to study employers' preferences had been published. Between 2010 and 2018, over 30 appeared. It is also obvious that there is a marked cluster of FSA users. Dutch-based FSA studies account for 15 papers, with German-based studies the next highest at seven and the US with six. This is partly explained by the fact that the Dutch LISS Panel (Longitudinal Internet Studies for the Social sciences) includes an FSA component, though only three papers use this as the basis for their research. The German PASS Panel (Labour Market and Social Security survey) also includes an FSA component, and the Understanding Society survey in Britain includes an FSA section for their 1500-member Innovation Panel.

21 of the papers use a sample of professionals - HR managers or company executives or owners. These respondents are either drawn from the panel studies outlined above or specifically assembled for the research in question. A further two studies use samples of professionals and business students. From these 23 papers, we focus on 16 that specifically cover recruitment and hiring processes. The appendix provides a brief summary of all the studies found (Table A.1), as well as a more detailed overview of the 16 reviewed here (Table A.2). All the papers in the following section have been published in peer-reviewed journals.

We discuss the papers in terms of their main topics: hiring and firing of older workers (five papers), migrant discrimination (two papers) and education and skills 
(six papers). A short section on miscellaneous, more recent papers completes the review.

\subsubsection{Older Workers}

Understanding the effects and consequences of an ageing workforce is critical to responding to demographic changes. Radl (2012) argues that although there is a policy consensus on encouraging older workers to remain in the workforce in Europe, this has yet to be translated to increasing employment rates for older people; while Jyrkinen and McKie (2012) suggest that discrimination against older workers is common but especially pervasive for female workers, who accumulate less economic capital across their working lives than men. In recent times, however, Larsen and Pedersen (2017) chart an increase in workforce participation among over-65s in Germany and Sweden, with a smaller increase in Denmark, driven largely by policies encouraging older workers. Nine papers have used FSA to study this issue, five of which are published in peer-reviewed journals and will be discussed here. All were written by Dutch researchers and have considerable authorship overlap, with retirement issues and hiring of older employers as a recurring theme. Henkens et al. (2009) use FSA to evaluate the circumstances in which an older worker will be offered early retirement or encouraged to continue working. Running a small scale survey of 22 middle managers in Dutch government departments, 4 managers from large Dutch multinationals and 25 business students, they construct vignettes with dimensions regarding the position the older employee holds, exogenous pressures on the organisation, and personal characteristics of the employee: knowledge, experience, health, and attitudes to retirement (Henkens et al. 2009, 1586-1587). They find that a worker's positive attitude and good health are important in keeping older workers on, with looking forward to retirement a strong signal for offering early retirement (Henkens et al. 2009, 1578).

Karpinska et al. (2011) tackle the subject from a different angle. Again with a small sample of managers from seven different economic sectors (20) and business students (17), they explore the circumstances in which an early-retired person may be hired, finding that the business cycle, especially in terms of labour-force short ages, is key to managers when considering a rehire of a retired person (Karpinska et al. 2011, 583). Mulders et al. (2014) use the LISS Panel to implement an FSA survey among 443 managers. They examine the inclination of managers to rehire workers older than the mandatory retirement age, finding that willingness to work for a lower wage is the most important aspect, though managers are in general not willing to employ these workers (Mulders et al. 2014, 428-429). A final paper on the same subject, from Karpinska et al. (2013), reports a different result. Through an FSA survey of 238 managers from the LISS Panel, they find that keeping workers beyond the retirement age is unpopular amongst employers. However, keeping workers on may be considered if the employer holds older workers generally in high 
regard, if there are labour market shortages, or if the worker in question is perceived as being diligent and in good health (Karpinska et al 2013, 1333).

Training opportunities for older workers is the subject of another paper by Karpinska et al. (2015). Again through the LISS Panel, they conduct a vignette study of 153 managers. Vignettes contain dimensions of financial situation of the organisation, age, sex, health, full or part-time work, work performance, and work attitude (Karpinska et al. 2015, 108). They find that training opportunities are generally not afforded to older workers, and that their possibilities decrease even further with age or if the worker is in poor health. On the other hand, a perceived positive attitude of an older worker increases the likelihood of further training being offered (Karpinska et al. 2015, 108-110).

The range of issues surrounding older workers studied by FSA is broad and the context (Dutch) is narrow. Furthermore, all of the papers suffer from a lack of depth in their results: sector-level differences or differences based on the size of the firm would be interesting to know but are left out of the analysis. This may be due to sample sizes too small to disaggregate into different sectors, or the fact that the LISS survey does not contain adequate information on this topic. However, a number of interesting results can be seen. First, an older employee's health and work attitudes are key in considerations of retirement, employment, and training. Good health and a positive attitude towards remaining in work are seen as positive signals. Second, a slack or tight labour market (abundance or shortage of labour supply) may influence employers' decisions about older workers. A tight labour market may mean deciding to defer the retirement of some older workers. Surprisingly, Henkens et al. suggest that "retirement is primarily regarded as a sovereign decision of the older worker" (Henkens et al. 2009, 1579), while there is some disagreement between the papers as to whether or not age norms held by employers do (Karpinksa et al. 2015, 1334) or do not (Karpinska et al. 2015, 110) affect decision-making. Nevertheless, FSA provides a useful window into the difficult decisions employers must take concerning workers reaching retirement age, by simulating many of the health and experience related questions that may come into play. While the literature cited here produces heterogenous results on what factors most affect employers' retaining or re-hiring older workers, a tight labour market, willingness of an older worker to accept reduced pay and flexible conditions, and the worker's general health emerge as three key factors influencing employers (often reluctant) hiring decisions.

\subsubsection{Migrant Discrimination}

The labour market experiences of migrants are a key focus for labour market sociology. The broad range of issues covered include the ethnic/migrant penalty (e.g. Ebner and Helbling 2016), skill transferability (Shan 2013), and employment precariousness (e.g. Potter and Hamilton 2014). FSA is beginning to be taken up 
as a means of analysing these areas, but has thus far been limited to discrimination and transferability of qualifications. A study of 242 Dutch managers by van Beek et al. (1997), seeks to determine how much experience, sex, and nationality matter in hiring. In a sobering result for non-natives and women, the paper shows that employers are willing to give up productivity - captured by experience and education - for a young, native, male worker, especially in a position with customer interface (van Beek et al. 1997, 314).

In Germany, Damelang and Abraham (2016) focus on foreign qualifications and their transferability from the country of origin to Germany. They survey 168 German CEOs and firm owners, with vignette dimensions of nationality, vocational certificate, work experience, age, last employer, type of position, and number of applications. Their results are better for migrants than those of van Beek et al., showing that although qualified Germans are preferred, applicants with a foreign certificate generally do well in recruitments - especially if they are from Western Europe. The real losers, according to the study, are unqualified workers, especially those from Eastern Europe (Damelang and Abraham 2016, 102-103).

In terms of migrant discrimination, then, FSA produces mixed results. On one hand, van Beek and colleagues find that an applicant's nationality overrides their other attributes. On the other, Damelang and Abraham show that qualifications are usually more important. Changing attitudes in the 15 years lying between the publication of these papers may explain this disparity, as may differences between the Dutch and German labour markets. Further FSA in this field could provide more information on employers' perceptions of race and nationality, especially given FSA's ability to reduce social desirability bias. As with the research on the ageing workforce, it would be interesting to see results disaggregated to the sector level, or more interest paid to the characteristics of respondents rather than the sole focus on the vignettes. What is clear is that FSA can be usefully deployed for questions of migration and ethnicity, as it can disentangle effects characteristics often assumed to be linked with migration (such as an expectation of lower or less prestigious education, willingness to accept poor work conditions and pay and a poorly developed social and professional network) from the fact of the migration itself, therefore more easily pinpointing pure discrimination based on ethnicity and migration status.

\subsubsection{Education and Skills}

With the subject of skills mismatch occupying the minds of many labour market scholars in recent times (e.g. Sparreboom and Tarvid 2016; Rohrbach-Schmidt and Tiemann 2016), employers strategies concerning education and skills is an important area of enquiry. The way in which employers assess the education of job applicants had been little studied, however, until a number of Dutch-based studies utilised FSA to investigate its use in employers' decision-making (de Wolf and van der Velden 2001; Biesma et al. 2007; Di Stasio 2014; Humburg and van der Velden 
2014; Di Stasio and van de Werfhorst 2016). Studying education through FSA is beneficial because it allows us to understand the way in which employers utilise education as a signal.

Education as a signal for recruiters is studied by Di Stasio (2014) in a survey of 59 Italian employers in the IT sector. Using dimensions of gender, work experience, an in-firm internship, field of study, grades, study duration, and extra curricular activities, she finds that in the Italian context, where education and grading systems are standardised but the links between education and the labour market are weak, good grades are the strongest signal of employability, while interning matters little (Di Stasio 2014, 806). The effects of the institutional context on education credentials are further studied by Di Stasio and van de Werfhorst (2016), this time surveying 38 employers in the Netherlands and 34 in England, again with a focus on the IT sector and vignettes containing similar dimensions as in Di Stasio (2014). They conclude that the type of educational institutions prevalent in the country have an important effect on the use of education as a signal. Amongst Dutch employers, where there is a stronger vocational education tradition than in Britain, a close match between the field of study or vocational training completed and the vacant occupation is considered important when considering applicants. British employers, on the other hand, treat education as a signal of trainability: what is studied is less important than grades, with academic performance of high importance to the English employers surveyed (Di Stasio and van de Werfhorst 2016, 22).

Another strand of educational signalling explored by FSA is the labour market utility of qualifications immediately following graduation. With unemployment becoming a greater issue amongst young workers worldwide, this topic is attracting increasing interest (James et al. 2013). Humburg and van der Velden point out that graduate job applications are "the first time [graduates] get reliable information on the labour market value of their credentials" $(2014,1)$. As with education in general, it is the employer who acts as the gatekeeper for the validity of educational qualifications, and as such it makes sense to ask him or her directly, rather than infer the value of qualifications indirectly.

Humburg and van der Velden's study encompasses nine European countries, and in an unusual design was left open in each country until 100 employers had completed the survey. Employers from the industries that hire the most graduates (excluding health and education) were invited to complete the survey: electro-technology, engineering, financial services, ICT, legal services, media and communication, and policy and organisation. Employers had to have hired graduates within the past five years. They find some cross-country differences - university prestige, for example, seems only to matter in Britain. Overall, however, they find that occupation-specific skills and communication skills bear by far the most importance in being hired. Still, the responses suggested that there is no perfect graduate profile, but that desired characteristics in a recent graduate vary strongly, depending on individual employer's 
preferences (Humburg and van der Velden 2014, 15-16). A similar paper by Biesma et al. (2007) focuses on public health services in the Netherlands, with 185 directors and managers responding to a discrete-choice experiment on skills preferences for graduate employees. Here they find that general skills are more valued by employers than occupation-specific skills. The authors argue that this is likely due to strong general skills signalling a high level of adaptability, an important attribute in this specific industry. The findings of these papers suggest then that the valuation of different types of skills depends on the context - notably the type of industry and institutional context of the country in question.

Differing levels of education affect the skills of job applicants, but the skills of recent graduates are difficult to quantify. The skills valued by employers seeking recent social science graduates are the subject of a paper by de Wolf and van der Velden (2001), who survey 27 Dutch employers of social science graduates by presenting them with candidates for three different types of jobs: management trainee, policymaker, or scientific researcher. The paper finds that different competences matter for different profiles - specific academic skills are valued for researchers, while soft skills are important for management trainees. Policy makers are best served by a mix of both. Other personal, non-academic skills such as communication and personality type are important for the job of a manager, but less so for the other two occupations (de Wolf and van der Velden 2001, 327).

Other studies analyse the interplay of social capital with education, and the effect of these two factors on job opportunities. Di Stasio and Gërxhani (2015) use FSA to study the role and importance of referrals from social contacts in recruitment. Their survey centres on the IT industry in England, with $34 \mathrm{HR}$ professionals taking part. This approach allows them to, on the one hand, see the role of referrals in conjunction with other signals, as well as the difference between formal (work-based) and informal referrals. They are also able to ascertain the effects of referrals on more than just the likelihood of an interview - their analysis covers both hiring and trainability. This demonstrates that FSA can be deployed in analysing employers' decisions relating to informal recruitment, or recruitment through social networks, which audit studies cannot easily capture. They find that while employers value a referral from an informal contact, the fact of being referred is not a bonus per se - it is the additional information provided by a referral that is valued most by employers. This, however, only holds for highly-educated job applicants - Those with less education are in fact penalised for being referred (Di Stasio and Gërxhani 2015, 103-104).

FSA focusing on education perhaps demonstrates the utility of the method in analysing the effects of signals the most clearly - education being a clear and often-used marker of anticipated productivity and reliability. Where FSA is most effective is in uncovering this effect in the recruitment process, where judgements based on education as a signal are first formed. This is a hard-to-reach moment in 
other forms of recruitment research but a critical one in the hiring process. The research reviewed here shows that education is indeed a vital signal for recruiters, but that what it signals is not necessarily clear-cut, and that different types of education are valued differently across occupational and geographical contexts.

\subsection{Recent and further applications}

Clearly, FSA's usage in employer-based settings is on the increase. However, it is also apparent that its use remains concentrated in a small number of areas and a small number of regions. Furthermore, in a number of instances, the studies use only small sample sizes. This produces interesting illustrative data but weakens external validity. Using FSA with larger sample sizes would be a step forward: moreover, it often seems that by incorporating FSA into their analysis, researchers are liable to disregard the characteristics of the respondents. Information on the sector and the firm size of the employer surveyed, as well as their own personal characteristics (e. g. age, sex, education) is highly relevant and would add depth to the analysis.

FSA has clear advantages for the analysis of signals and indices. This could be exploited by integrating into factorial surveys further characteristics considered as signals, such as marital status and children - which could act as signals of work commitment and productivity, but also unveil employers' gender stereotypes. While they have sometimes been added as control variables, they had not been a direct focus of FSA until Liechti et al. (2017) used an employer-based survey in Switzerland and Germany to measure the signalling impact of Active Labour Market Programmes, finding that while ALMP participation can be a positive signal, it depends significantly on the type of job and "distance" from the labour market of the applicant (Liechti et al. 2017, 264-265). Shi et al. (2018) also test the impact of unemployment scarring employers' decision-making, responding to advertised job vacancies in Switzerland with a request to complete a factorial survey a strategy which helps the results more closely reflect the current reality of the job market. They find that while unemployment reduces the probability to be hired, this can be mitigated if a candidate has vocational training for the occupation in question (Shi et al. 2018, 12). Outcomes for women in the workforce, and the effects of the choice to have children, are becoming more important as women's tertiary graduation rates begin to outpace men's, and women increasingly remain in the workforce once they have children (OECD 2015). FSA can integrate these characteristics into vignettes alongside other important signals, like education, experience, and referrals, adding to the literature on a fast-changing labour market, the nature of which affects women and young mothers especially (Correll et al. 2007). FSA has been shown to be useful in measuring discrimination against women (see Jasso and Webster 1997; 1999; Auspurg et al. 2017), but as yet only Oesch et al. (2017), using a factorial survey targeting the members of a Swiss Human Resources association, have carried out employer-based research in this area. They show that employer decisions play 
a role in the motherhood wage penalty in Switzerland, with respondents offering mothers wages up to $3 \%$ lower, on average, than those offered to childless women. They also found that this penalty varies greatly depending on the age of the mother (younger mothers receiving penalties of up to 6\%) and her occupation.

Apart from outcomes for older workers, FSA has not been broadly used for indices, or those characteristics that cannot be changed. To date the study of indices has been largely left to audit studies, mostly correspondence audits, or through inference from survey data. Recent correspondence audit studies have focused on topics such as race and ethnicity in low-skilled occupations in New York City (e.g. Pager et al. 2009) and on the signalling effect of cognitive and non-cognitive skills (e.g. Protsch and Solga 2015). However, these analyses can go no further than ascertaining if their profiles were adequate enough to be called for interview. Further, they cannot control for respondent characteristics beyond what is publicly known, unless they are followed up with a survey or interview. This leaves an opening for FSA, which could provide more information on these indices.

There are further indices used by employers that would benefit from further probing by FSA. Indeed, FSA has shown its utility in questions of age, especially related to retired workers, but also indirectly with younger workers. Older workers face a different set of issues, including the reticence of employers to invest in workers with fewer years left before retirement, concerns surrounding their trainability, and higher wages compared to younger workers, which could be probed with FSA. Of course, social desirability remains a concern whenever topics such as age and race are raised, but when formulated correctly FSA vignettes may provide denser, more reliable information to complement what is currently a paucity of sociological analysis.

\section{Conclusion}

The analytical options available to the quantitative sociological researcher have expanded in recent years and, in the case of labour market sociology, mechanisms on both the supply and demand side can be more readily analysed than ever. Factorial survey analysis is one example of these new methods. It is particularly well-suited to the study of the demand (employer) side of the labour market equation, as it can target recruiters directly and present both complex and varying worker profiles for judgement. These judgements can then in turn be analysed for evidence of employer preferences based on certain characteristics, such as gender, age, nationality or educational attainment. By ensuring that all the dimensions are uncorrelated and eliminating unobserved heterogeneity, FSA satisfies the criteria for causal design.

FSA should not, however, be blindly accepted as the panacea for a lack of reliable demand-side data. Respondents are aware that they are participating in a survey and may therefore be prone to deliver socially desirable responses. Moreover, 
the fact that FSA is not carried out in a real-world setting means that all the judgements made are based on hypothetical situations and can therefore be considered behavioural intentions that may not be replicated in real recruitment scenarios. Finally, FSA is by design an exercise in simplification, where only a few examples (of occupations, for instance) can be judged. Its results may thus not be readily generalisable and therefore FSA, while being internally valid, is not externally valid in all circumstances.

These criticisms do not suffice to discredit the use of FSA in labour market sociology. Rather, they plead for a holistic approach to its use. Comparisons with labour force and employer surveys, audit studies and field experiments may all provide opportunities to increase external validity and compare preferences expressed within the vignette survey setting with real-world data. Vignette surveys may be embedded within larger surveys to increase sample size (Karpinska et al. 2013; Auspurg et al. 2017). To better reflect actual issues and trends on the labour market, recruiters currently hiring could be invited to complete a survey based on their job advertisements, an approach currently being pioneered by the NEGOTIATE project (see Shi et al. 2018). With thoughtful implementation and interpretation, FSA can be very useful in pinpointing the factors and influences that play a part in labour market outcomes.

\section{References}

Abraham, Martin, Katrin Auspurg, and Thomas Hinz. 2010. Migration Decisions Within Dual-Earner Partnerships: A Test of Bargaining Theory. Journal of Marriage and Family 72(4): 876-892.

Abraham, Martin, Katrin Auspurg, Sebastian Bähr, Corinna Frodermann, Stefanie Gundert, and Thomas Hinz. 2013. Unemployment and Willingness to Accept Job Offers: Results of a Factorial Survey Experiment. Journal for Labour Market Research 46(4): 283-305.

Aguinis, Herman and Kyle Bradley. 2014. Best Practice Recommendations for Designing and Implementing Experimental Vignette Methodology Studies. Organizational Research Methods 17(4): 351-371.

Auspurg, Katrin and Thomas Hinz. 2015. Factorial Survey Experiments. Quantitative Applications in the Social Sciences 175. Los Angeles: Sage.

Auspurg, Katrin and Stefanie Gundert. 2015. Precarious Employment and Bargaining Power: Results of a Factorial Survey Analysis. Zeitschrift Für Soziologie 44(2): 99-117.

Auspurg, Katrin, Thomas Hinz, and Carsten Sauer. 2017. Why Should Women Get Less? Evidence on the Gender Pay Gap From Multifactorial Survey Experiments. American Sociological Review 82(1): 179-210.

Baert, Stijn and Ann-Sophie De Pauw. 2014. Is Ethnic Discrimination Due to Distaste or Statistics? Economics Letters 125(2): 270-273.

Bähr, Sebastian and Martin Abraham. 2016. The Role of Social Capital in the Job-Related Regional Mobility Decisions of Unemployed Individuals. Social Networks 46(July): 44-59.

Behrenz, Lars. 2001. Who Gets the Job and Why? An Explorative Study of Employers' Recruitment Behaviour. Journal of Applied Economics IV(2): 255-278. 
Bennett, Roger. 2002. Employers' Demands for Personal Transferable Skills in Graduates: A Content Analysis of $1000 \mathrm{Job}$ Advertisements and an Associated Empirical Study. Journal of Vocational Education \& Training 54(4): 457-476.

Biesma, R. G., M. Pavlova, G. G. van Merode, and W. Groot. 2007. Using Conjoint Analysis to Estimate Employers Preferences for Key Competencies of Master Level Dutch Graduates Entering the Public Health Field. Economics of Education Review 26(3): 375-386.

Bonoli, Giuliano and Karl Hinrichs. 2012. Statistical Discrimination and Employers' Recruitment: Practices for Low-Skilled Workers. European Societies 14(3): 338-361.

Breen, Richard, Damain Hannan, and Richard O'Leary. 1995. Returns to Education: Taking Account of Employers' Perceptions and Use of Educational Credentials. European Sociological Review 11(1): 59-73.

Connelly, Brian L., S. Trevis Certo, R. Duane Ireland, and Christopher R. Reutzel. 2011. Signaling Theory: A Review and Assessment. Journal of Management 37(1): 39-67.

Correll, Shelley J., Stephen Benard, and In Paik. 2007. Getting a Job: Is There a Motherhood Penalty? American Journal of Sociology 112(5): 1297-1338.

Damelang, Andreas and Martin Abraham. 2016. You Can Take Some of It with You! A Vignette Study on the Acceptance of Foreign Vocational Certificates and Ethnic Inequality in the German Labour Market. Zeitschrift Für Soziologie 45(2): 91-106.

De Wolf, Inge and Rolf van der Velden. 2001. Selection Processes for Three Types of Academic Jobs: An Experiment Among Dutch Employers of Social Sciences Graduates. European Sociological Review 17(3): 317-330.

Di Stasio, Valentina. 2014. Education as a Signal of Trainability: Results From a Vignette Study With Italian Employers. European Sociological Review 30(4): 796-809.

Di Stasio, Valentina and Klarita Gërxhani. 2015. Employers' Social Contacts and Their Hiring Behaviour in a Factorial Survey. Social Science Research 51: 93-107.

Di Stasio, Valentina and Herman G. van de Werfhorst. 2016. Why Does Education Matter to Employers in Different Institutional Contexts? A Vignette Study in England and the Netherlands. Social Forces 95(1): 77-106.

Ebner, Christian and Marc Helbling. 2016. Social Distance and Wage Inequalities for Immigrants in Switzerland. Work, Employment \& Society 30(3): 436-454.

Fernandez, Roberto and Nancy Weinberg. 1997. Sifting and Sorting: Personal Contacts and Hiring in a Retail Bank. American Sociological Review 62(6): 883-902.

Gaddis, S. Michael. 2018. An Introduction to Audit Studies in the Social Sciences. Pp. 3-44 in Audit Studies: Behind the Scenes With Theory, Method, and Nuance, edited by S. Michael Gaddis. Cham: Springer International Publishing.

Green, Paul, Abba Krieger, and Yoram Wind. 2001. Thirty Years of Conjoint Analysis: Reflections and Prospects. Interfaces, Marketing Engineering 31(3): 56-73.

Green, Paul and V. Srinivasan. 1990. Conjoint Analysis in Marketing: New Developments With Implications for Research and Practice. Journal of Marketing 54(4): 3-19.

Hainmueller, Jens, Daniel Hopkins, and Teppei Yamamoto. 2014. Causal Inference in Conjoint Analysis: Understanding Multidimensional Choices via Stated Preference Experiments. Political Analysis 22: $1-30$.

Hainmueller, Jens, Daniel Hopkins, and Teppei Yamamoto. 2015. Validating Vignette and Conjoint Survey Experiments Against Real-World Behavior. Proceedings of the National Academy of Sciences 112(8): 2395-2400.

Henkens, Kène, Hanna van Solinge, and Rabina Cozijnsen. 2009. Let Go or Retain? A Comparative Study of the Attitudes of Business Students and Managers about the Retirement of Older Workers. Journal of Applied Social Psychology 39(7): 1562-1588. 
Holzer, Harry J., Steven Raphael, and Michael A. Stoll. 2006. Employers in the Boom: How Did the Hiring of Less-Skilled Workers Change During the 1990s? The Review of Economics and Statistics 88(2): 283-299.

Humburg, Martin and Rolf van der Velden. 2014. Skills and the Graduate Recruitment Process: Evidence From Two Discrete Choice Experiments. Research Centre for Education and the Labour Market.

James, Susan, Chris Warhurst, Gerbrand Tholen, and Johanna Commander. 2013. What We Know and What We Need to Know About Graduate Skills. Work, Employment \& Society 27(6): 952-963.

Jasso, Guillermina. 2006. Factorial Survey Methods for Studying Beliefs and Judgments. Sociological Methods \& Research 34(3): 334-423.

Jasso, Guillermina and Murray Webster. 1999. Assessing the Gender Gap in Just Earnings and Its Underlying Mechanisms. Social Psychology Quarterly 62(4):367-380.

Jasso, Guillermina and Murray Webster. 1997. Double Standards in Just Earnings for Male and Female Workers. Social Psychology Quarterly 60(1): 66-78.

Jyrkinen, Marjut and Linda McKie. 2012. Gender, Age and Ageism: Experiences of Women Managers in Finland and Scotland. Work, Employment \& Society 26(1): 61-77.

Karpinska, Kasia, Kène Henkens, and Joop Schippers. 2013. Retention of Older Workers: Impact of Managers' Age Norms and Stereotypes. European Sociological Review 29(6): 1323-1335.

Karpinska, Kasia, Kène Henkens, and Joop Schippers. 2011. The Recruitment of Early Retirees: A Vignette Study of the Factors That Affect Managers' Decisions. Ageing and Society 31(4): 570-589.

Karpinska, Kasia, Kène Henkens, Joop Schippers, and Mo Wang. 2015. Training Opportunities for Older Workers in the Netherlands: A Vignette Study. Research in Social Stratification and Mobility 41: 103-112.

Larsen, Mona and Peder J. Pedersen. 2017. Labour Force Activity after 65: What Explain Recent Trends in Denmark, Germany and Sweden? Journal for Labour Market Research 50(1): 15-27.

Larsen, Christian and Patrik Vesan. 2012. Why Public Employment Services Always Fail. Double-Sided Asymmetric Information and the Placement of Low-Skill Workers in Six European Countries. Public Administration 90(2): 466-479.

Liechti, Fabienne, Flavia Fossati, Giuliano Bonoli, and Daniel Auer. 2017. The Signalling Value of Labour Market Programmes. European Sociological Review 33(2): 257-274.

McDermott, Rose. 2011. Internal and External Validity. Pp. 27-40 in Cambridge Handbook of Experimental Political Science, edited by James Druckman, Donald Green, James Kuklinski, and Arthur Lupia. Cambridge: Cambridge University Press.

Mulders, Jaap, Hendrik van Dalen, Kène Henkens, and Joop Schippers. 2014. How Likely Are Employers to Rehire Older Workers after Mandatory Retirement? A Vignette Study Among Managers. De Economist 162: 415-431.

OECD. 2015. Education at a Glance 2015: OECD Indicators. Paris: OECD Publishing.

Oesch, Daniel, Oliver Lipps, and Patrick McDonald. 2017. The Wage Penalty for Motherhood: Evidence on Discrimination From Panel Data and a Survey Experiment for Switzerland. Demographic Research 37(December): 1793-1824.

Pager, Devah and Lincoln Quillian. 2005. Walking the Talk? What Employers Say Versus What They Do. American Sociological Review 70(3): 355-380.

Pager, Devah, Bruce Western, and Bart Bonikowski. 2009. Discrimination in a Low-Wage Labor Market: A Field Experiment. American Sociological Review 74(5): 777-799.

Petersen, Trond, Ishak Saporta, and Marc-David Seidel. 2000. Offering a Job: Meritocracy and Social Networks. American Journal of Sociology 106(3): 763-816.

Potter, Michael, and Jennifer Hamilton. 2014. Picking on Vulnerable Migrants: Precarity and the Mushroom Industry in Northern Ireland. Work, Employment \& Society 28(3): 390-406. 
Protsch, Paula and Heike Solga. 2015. How Employers Use Signals of Congnitive and Noncognitive Skills and Labour Market Entry: Insights From Field Experiments. European Sociological Review 31(5): 521-532.

Radl, Jonas. 2012. Too Old to Work, or Too Young to Retire? The Pervasiveness of Age Norms in Western Europe. Work, Employment \& Society 26(5): 755-771.

Rohrbach-Schmidt, Daniela and Michael Tiemann. 2016. Educational (Mis)match and Skill Utilization in Germany: Assessing the Role of Worker and Job Characteristics. Journal for Labour Market Research 49(2): 99-119.

Rossi, Peter. 1951. The Application of Latent Structure Analysis to the Study of Social Stratification. $\mathrm{PhD}$ Thesis, Columbia University.

Rossi, Peter, and Steven Nock. 1982. Measuring Social Judgements: The Factorial Survey Approach. Los Angeles: Sage.

Ryan, Mandy, Bate, Angela, Eastmond, Clifford J. and Ludbrook, Anne. 2001. Use of Discrete Choice Experiments to Elicit Preferences. Quality in Health Care 10(Suppl I): 55-60.

Sacchi, Stefan, Irene Kriesi, and Marlis Buchmann. 2016. Occupational Mobility Chains and the Role of Job Opportunities for Upward, Lateral and Downward Mobility in Switzerland. Research in Social Stratification and Mobility 44(June): 10-21.

Sauer, Carsten, Katrin Auspurg, Thomas Hinz, and Stefan Liebig. 2011. The Application of Factorial Surveys in General Population Samples: The Effects of Respondent Age and Education on Response Times and Response Consistency. Survey Research Methods 5(3): 89-102.

Shan, Hongxia. 2013. Skill as a Relational Construct: Hiring Practices From the Standpoint of Chinese Immigrant Engineers in Canada. Work, Employment \& Society 27(6): 915-931.

Shi, Lulu P., Christian Imdorf, Robin Samuel, and Stefan Sacchi. 2018. How Unemployment Scarring Affects Skilled Young Workers: Evidence From a Factorial Survey of Swiss Recruiters. Journal for Labour Market Research 52(7): 1-15.

Sparreboom, Theo and Alexander Tarvid. 2016. Imbalanced Job Polarization and Skills Mismatch in Europe. Journal for Labour Market Research 49(1): 15-42.

Spence, Michael. 1973. Job Market Signaling. The Quarterly Journal of Economics 87(3): 355-374.

Taylor, Brian J. 2005. Factorial Surveys: Using Vignettes to Study Professional Judgement. British Journal of Social Work 36 (7): 1187-1207.

Taylor, Philip and Alan Walker. 1994. The Ageing Workforce: Employers' Attitudes Towards Older People. Work, Employment and Society 8(4): 569-591.

Thurow, Lester C. 1975. Generating Inequality: Mechanisms of Distribution in the US Economy. New York: Basic Book.

Van Beek, Krijn, Carl Koopman, and Bernard van Praag. 1997. Shopping at the Labour Market: A Real Tale of Fiction. European Economic Review 41: 295-317.

Wallander, Lisa. 2009. 25 Years of Factorial Surveys in Sociology: A Review. Social Science Research 38: 505-520.

Winship, Christopher and Stephen Morgan. 1999. The Estimation of Causal Effects From Observational Data. Annual Review of Sociology 25: 659-709. 


\section{$7 \quad$ Appendix}

Table A.1 Summary of FSA papers in labour market sociology

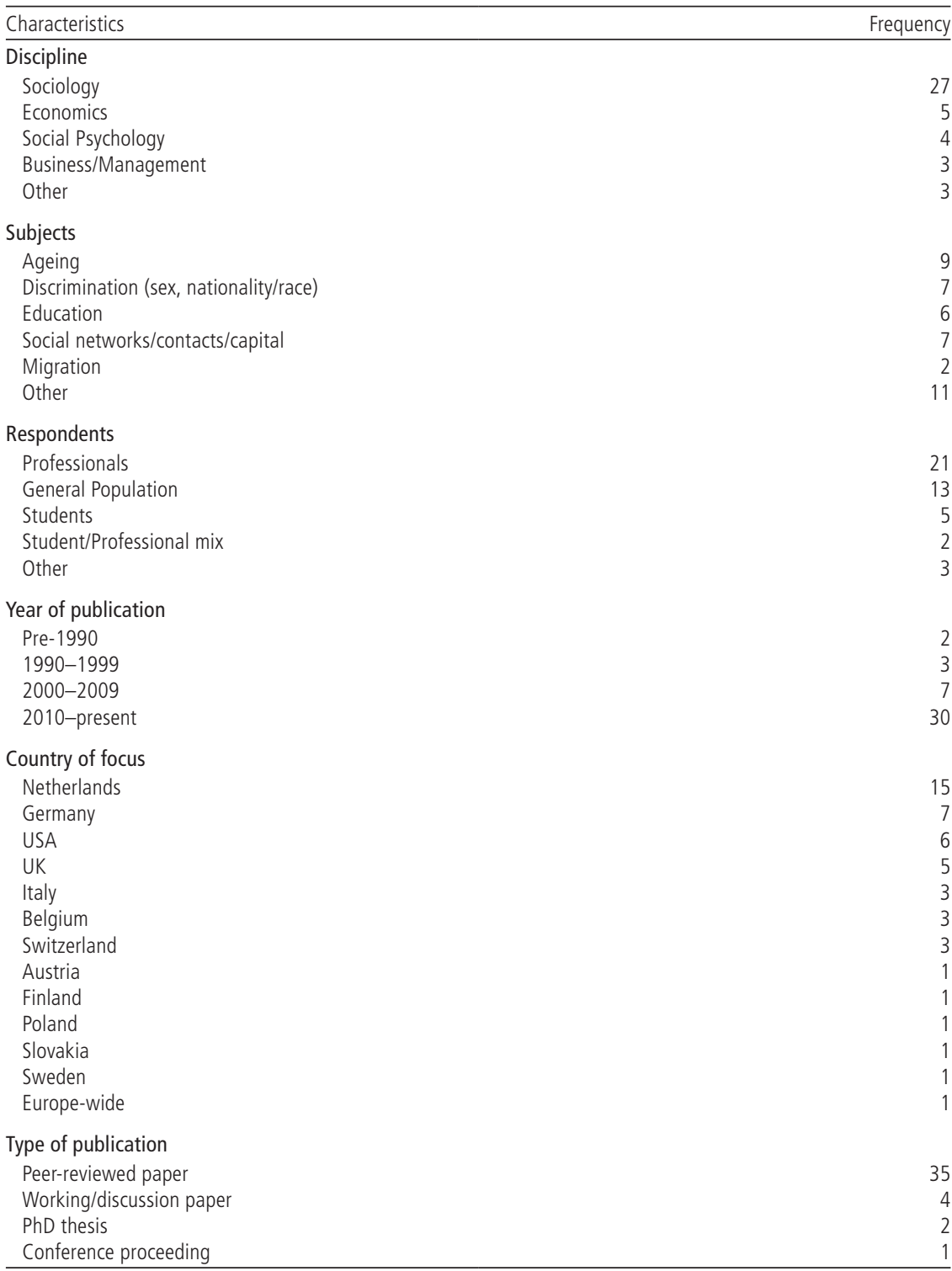




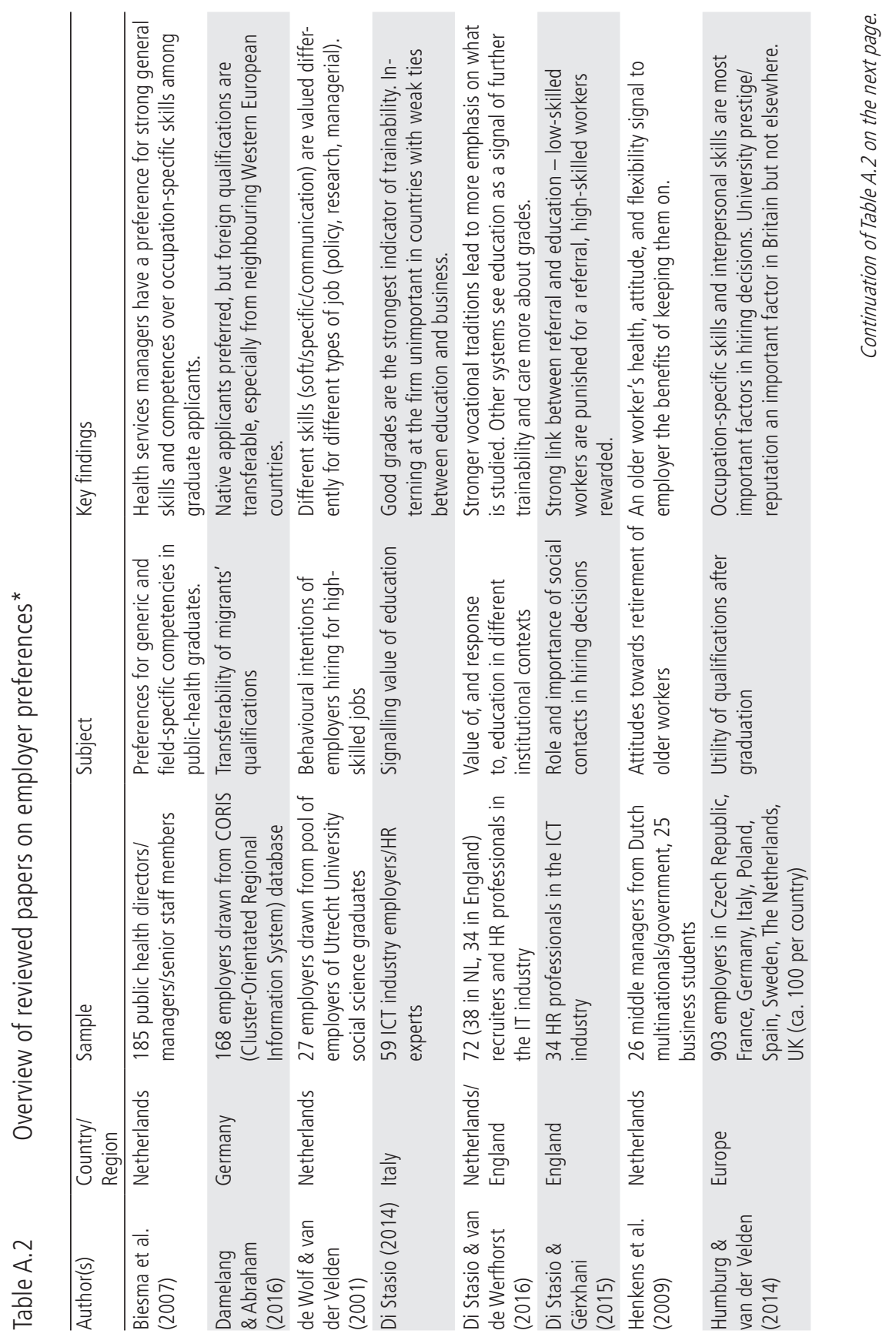




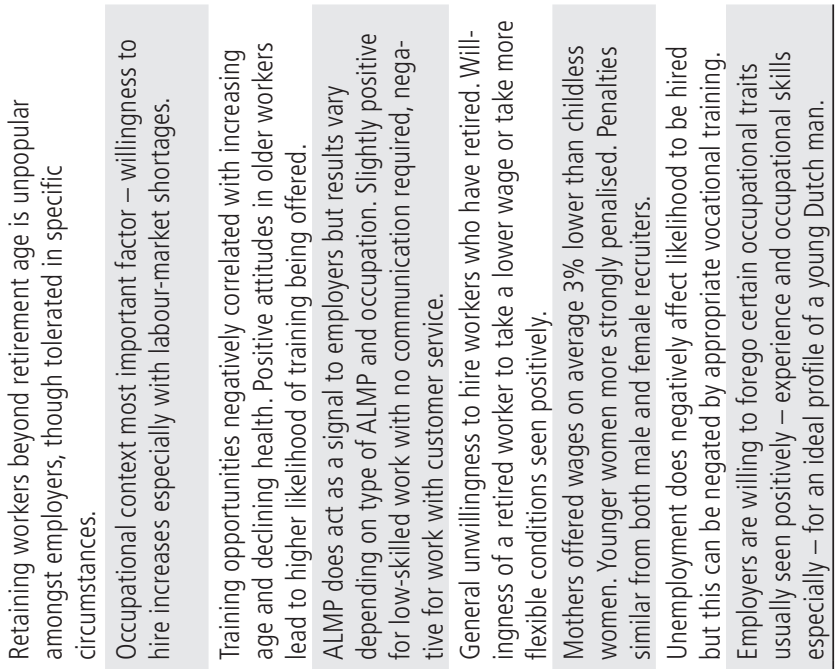

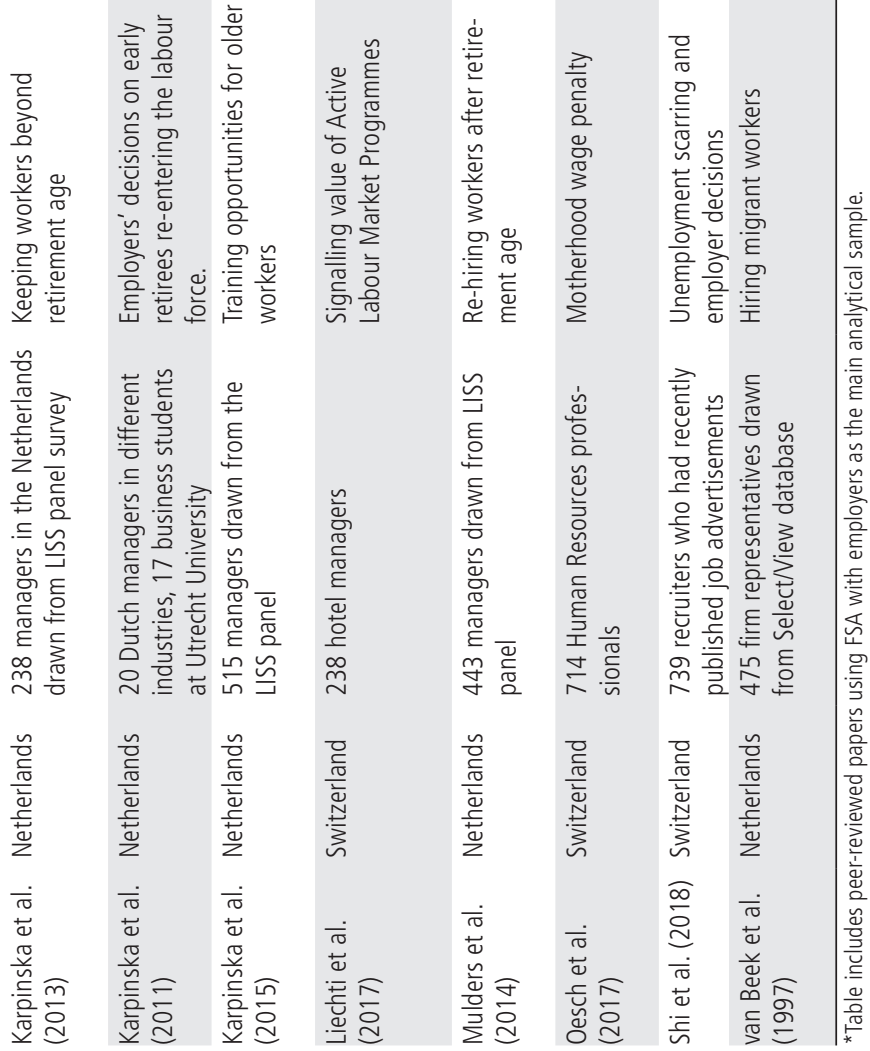

